\title{
Stable isotope ratios in harbor seal Phoca vitulina vibrissae: effects of growth patterns on ecological records
}

\author{
Liying Zhao ${ }^{1,2, *}$, Donald M. Schell ${ }^{1}$ \\ ${ }^{1}$ Institute of Marine Science, School of Fisheries and Ocean Sciences, University of Alaska Fairbanks, PO Box 757220 , \\ Fairbanks, Alaska 99775, USA \\ ${ }^{2}$ Present address: UC Davis Stable Isotope Facility, 3112 Plant \& Environmental Sciences Bldg, \\ University of California, Davis, California 95616, USA
}

\begin{abstract}
Growth rates and patterns of vibrissae (whiskers) in captive harbor seals Phoca vitulina were examined by intravenous infusion of ${ }^{15} \mathrm{~N}$-labeled amino acid tracers to mark their keratinous tissues. The use of vibrissa segmental isotopic analysis as diet indicators was evaluated during controlled feeding trials. Harbor seals shed their vibrissae annually. Replacement of new vibrissae started in May or June, depending on individual seals. Growth rates of new vibrissae were very fast at up to $0.78 \mathrm{~mm} \mathrm{~d}^{-1}$ during summer and fall, and then changed to a much slower growth rate throughout winter and early spring. An average growth rate of $0.075 \mathrm{~mm} \mathrm{~d}^{-1}$ was obtained from 1 vibrissa from December to May. $\delta^{13} \mathrm{C}$ and $\delta^{15} \mathrm{~N}$ values in vibrissae co-varied and reflected temporal variations of diet or habitat changes of seals, particularly over a rapid growth period from late spring to fall. Compared with other tissues such as blood components, vibrissae can be sampled less invasively and archive ecological records over a longer period. Vibrissa segmental isotopic analysis provides a more flexible tool for studying foraging ecology of wild seals, despite the varying seasonal growth rates and annual replacements.
\end{abstract}

KEY WORDS: Vibrissae $\cdot$ Growth patterns $\cdot$ Foraging ecology $\cdot$ Stable isotopes $\cdot$ Pinnipeds

\section{INTRODUCTION}

The western stock of Steller sea lions and harbor seals in Alaska has declined dramatically over the past 3 decades (Pitcher 1990, Frost et al. 1994). A regime shift, driven by climate changes, has resulted in changes in prey fish species in the Bering Sea ecosystems (Beamish 1993, Anderson \& Piatt 1999). In particular, changes in forage fish assemblages from predominantly small fatty fish species, such as herring, to lower fat/lower energy density fish species, such as pollock, might have caused nutritional deficiency in seals and sea lions, and partially contributed to their population declines (Alaska Sea Grant 1993, Rosen \& Trites 2000). Consequently, it is important to understand the diet and habitat changes of these marine mammal species for a better understanding of their nutritional physiology and population trends.
Stable isotope techniques have increasingly been used to study foraging ecology of pinnipeds (Hobson et al. 1996, 1997, Burton \& Koch 1999, Hirons et al. 2001, Kurle \& Worthy 2001, Lesage et al. 2001, Kurle 2002). Variations in natural abundances of $\delta^{13} \mathrm{C}$ and $\delta^{15} \mathrm{~N}$ in consumer tissues can provide integrated dietary information over differing timescales, ranging from days (plasma, serum, whole blood) to weeks (muscle, red blood cells) or months (hair, fur, whiskers), depending on metabolic activity of different types of tissue (Tieszen et al. 1983, Hobson \& Clark 1992). Due to the keratinous structure and metabolic inertness of vibrissae, variations of carbon and nitrogen isotopic signatures along vibrissa length in Steller sea lions and harbor seals may archive temporal ecological records over longer periods (Hirons et al. 2001), and hence, provide a useful tool to track relatively long-term dietary and foraging information of pinnipeds. However, the potential to use vibrissa segmental isotopic 
analysis as diet indicators requires knowledge of growth patterns and rates of vibrissae in different pinniped species. In this paper, we present a study from captive harbor seals during controlled feeding trials, conducted at the Alaska SeaLife Center from September 1998 to September 2000. Growth patterns and rates of vibrissae were examined by assigning a time axis using ${ }^{15} \mathrm{~N}$-labeled amino acid tracers to mark their keratinous tissues. The use of natural abundance $\delta^{13} \mathrm{C}$ and $\delta^{15} \mathrm{~N}$ variations along the length of metabolically inactive vibrissae as diet indicators were also tested, as the diet of captive seals was known and well controlled in this study. The effects of growth patterns and rates on isotopic compositions and vibrissa sampling time were discussed for a better interpretation of isotopic signatures preserved along vibrissa length of wild seals.

\section{MATERIALS AND METHODS}

Animal handling and feeding trials. Controlled feeding trials were conducted from September 1998 to September 2000 at the Alaska SeaLife Center (ASLC) in Seward, Alaska. Seals were housed in large outdoor pools and fed ad libitum predominantly on Pacific herring for 3 mo before a 2 yr crossover repeated feeding trial started in September 1998 (Table 1). Two natural prey fish, Pacific herring Clupea pallasi and walleye pollock Theragra chalcogramma, were alternatively fed to the seals and 3 seals were included in this study. As shown in Table 1, Snapper, a 15 yr old male, was fed on an equal mix of herring and pollock as a control for the entire trial. Pender, a 3 yr old male, was first fed herring, then pollock, and switched to herring every 4 mo. Poco, a 23 yr old female, was initially fed pollock and switched to the alternative diet at the same time as Pender, but in reverse order.

${ }^{15} \mathrm{~N}$-labeled amino acid tracer administration. Theoretically, many ${ }^{15} \mathrm{~N}$-labeled amino acids can serve as tracers to mark vibrissae. However, ${ }^{15} \mathrm{~N}$-labeled glycine might be a preferred tracer due to the fact that (1) it is inexpensive compared to other amino acid tracers, (2) a smaller amount of glycine is required for infusion to produce the same ${ }^{15} \mathrm{~N}$ enrichment as other amino acids because of its low molecular weight. In addition, vibrissae are composed of a high percentage of glycine residues that are essential to the tight, $\alpha$ helical keratinous structures. Hence, ${ }^{15} \mathrm{~N}$-labeled glycine was infused intravenously into all 3 seals (Snapper and Poco on 8 December 1998, Pender on 16 December 1998) during the first tracer experiment. To minimize animal handling and to coordinate it with other concurrent studies, $3{ }^{15} \mathrm{~N}$-labeled essential amino acids, leucine, valine and phenylalanine, were also used and infused, respectively, into Snapper, Poco and Pender on 21 June 2000 during a second tracer experiment. Table 2 summarizes the 2 tracer experiments and vibrissa sampling information.

Table 2. Tracer experiments and vibrissa sampling information

\begin{tabular}{|c|c|c|c|c|c|}
\hline Seal & Tracer type & Infusion date & $\begin{array}{c}\text { Vibrissa } \\
\text { sampling date }\end{array}$ & $\begin{array}{l}\text { Days following } \\
\text { tracer infusion }\end{array}$ & $\begin{array}{c}\text { Vibrissa } \\
\text { length }(\mathrm{cm})\end{array}$ \\
\hline \multirow[t]{5}{*}{ Pender, male, 2.5 yr } & 1st dose: ${ }^{15} \mathrm{~N}$-glycine & 16 Dec 98 & 19 Dec 98 & 4 & 8.8 \\
\hline & & & 25 Feb 99 & 72 & 3.8 \\
\hline & & & 20 May 99 & 156 & 2.0 \\
\hline & & & 16 Sep 99 & 275 & 10 \\
\hline & 2nd dose: ${ }^{15} \mathrm{~N}$-phenylalanine & 21 Jun 00 & 5 Sep 00 & 77 & 6.3 \\
\hline \multirow[t]{4}{*}{ Poco, female, 23 yr } & 1st dose: ${ }^{15} \mathrm{~N}$-glycine & 8 Dec 98 & 8 Dec 98 & 0 & 10 \\
\hline & & & 18 May 99 & 162 & 6.2 \\
\hline & & & 15 Sep 99 & 282 & 10 \\
\hline & 2nd dose: ${ }^{15} \mathrm{~N}$-valine & 21 Jun 00 & 5 Sep 00 & 77 & 6.0 \\
\hline \multirow[t]{3}{*}{ Snapper, male, 15 yr } & 1st dose: ${ }^{15} \mathrm{~N}$-glycine & 8 Dec 98 & 8 Dec 98 & 0 & 10 \\
\hline & & & 15 Sep 99 & 282 & 10 \\
\hline & 2nd dose: ${ }^{15} \mathrm{~N}$-leucine & 21 Jun 00 & 5 Sep 00 & 77 & 6.0 \\
\hline
\end{tabular}


Amino acids enriched with ${ }^{15} \mathrm{~N}$ (95 to $99 \%$ ) (Cambridge Isotope Laboratories) were prepared in sterile saline solution, sealed in ampules and autoclaved for 25 min prior to injection. The concentrations of injection solution differed based upon solubility of different amino acids. The total amount of amino acid tracer infused was $0.5 \mathrm{~g}$ (glycine) or $1.0 \mathrm{~g}$ (others) per seal and proved to be sufficient to track the label. All the procedures were approved by the ASLC scientific committee, and conducted as required by the Institutional Animal Care and Use Committees of the University of Alaska and ASLC.

Stable isotope analysis. Vibrissae were clipped from the muzzle of seals at intervals, particularly after ${ }^{15} \mathrm{~N}$ labeled amino acid tracer infusions. Vibrissae were washed in distilled water in an ultrasonic cleaner, dried, further cleaned with steel wool and then sectioned at $\sim 2 \mathrm{~mm}$ intervals from base to tip for isotopic analysis. Blood samples were routinely collected at 2 wk intervals following an overnight fast. Serum (plain tubes, no additive added) was separated by clinical centrifugation immediately after blood withdrawal and frozen at $-80^{\circ} \mathrm{C}$. Serum samples were freeze-dried and ground to a powder for homogeneity for isotopic analysis. Carbon and nitrogen isotope ratios were measured using a Europa 20/20 continuous-flow isotope ratio mass spectrometer. Analytical precision of peptone standards was $\pm 0.1 \%$ for carbon and $\pm 0.2 \%$ o for nitrogen. Results are reported using standard $\delta$ notation in parts per thousand (\%) relative to Pee Dee Belemnite (VPDB) for $\delta^{13} \mathrm{C}$ and atmospheric $\mathrm{N}_{2}$ for $\delta^{15} \mathrm{~N}$ as follows:

$$
\delta X=\left[\left(R_{\text {samples }} / R_{\text {standard }}\right)-1\right] \times 1000
$$

where $\delta X$ is $\delta^{13} \mathrm{C}$ or $\delta^{15} \mathrm{~N}$, and $R$ is the ratio of ${ }^{13} \mathrm{C} /{ }^{12} \mathrm{C}$ or ${ }^{15} \mathrm{~N} /{ }^{14} \mathrm{~N}$.

\section{RESULTS}

\section{Growth patterns and rates inferred from ${ }^{15} \mathrm{~N}$-labeled tracer experiments}

Surprisingly, discrete ${ }^{15} \mathrm{~N}$ spikes were not observed in all vibrissae sampled in different periods following ${ }^{15} \mathrm{~N}$-glycine infusions. Enriched ${ }^{15} \mathrm{~N}$ markers were evident in 2 vibrissae from Pender, respectively sampled on Day 4 and Day 72, but not in those sampled on Day 156 and Day 275 (Fig. 1). An enriched $\delta^{15} \mathrm{~N}$ value of $26.2 \%$ was measured near the base of the Pender vibrissa sampled on Day 4. This value was lower than those simultaneously found in serum $(49.9 \%)$, but much higher than those in red blood cells $(18.0 \%)$, suggesting that the infused ${ }^{15} \mathrm{~N}$-labeled glycine immediately enters body pools and then rapidly incorporates into protein synthesis of vibrissae.

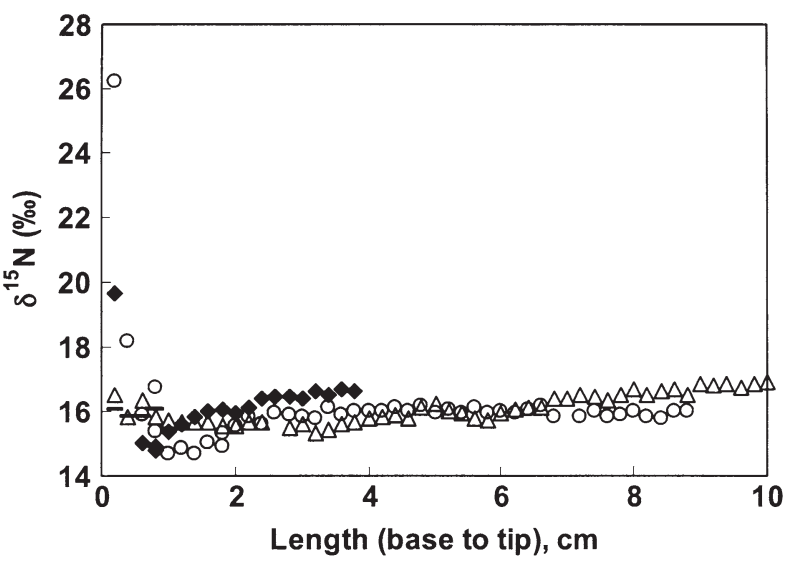

Fig. 1. Phoca vitulina. $\delta^{15} \mathrm{~N}$ values in vibrissae from Pender following the ${ }^{15} \mathrm{~N}$-glycine infusion. Vibrissae were respectively sampled on 19 December 1998 (O: Day 4); 25 February 1999 ( $\bullet$ : Day 72); 20 May 1999 ( $\Delta$ : Day 156) and 16 September 1999 (一: Day 275). Data at the base of vibrissae length $(0 \mathrm{~cm})$ represent the most recently grown vibrissae

In contrast to the third vibrissa from Pender, sampled on Day 156, the vibrissa from Poco sampled on Day 162 showed a peak of ${ }^{15} \mathrm{~N}$-enriched marker (Fig. 2a,b), but no marker was evident in vibrissae sampled on Day 282 from either Poco or Snapper (Fig. 3). The fact that the third vibrissa from Pender sampled on 20 May 1999 was very thin and short $(<2 \mathrm{~cm})$, and no enriched markers were evident in all 3 vibrissae sampled in September 1999 from all 3 seals, suggested that these vibrissae were newly grown. New vibrissae might have begun growth at some time before $20 \mathrm{May}$, i.e. in Pender. However, the peak of enriched ${ }^{15} \mathrm{~N}$ marker, as shown in Fig. 2a, indicated that the vibrissa from Poco had been retained for the entire period from 8 December 1998 to 18 May 1999. Assuming that ${ }^{15} \mathrm{~N}$-labeled glycine was incorporated into vibrissae immediately following its infusion, a $\delta^{15} \mathrm{~N}$ value of $27.4 \%$ at $1.2 \mathrm{~cm}$ from the base marked the initial incorporation of the infused tracer into this vibrissa (Fig. 2a,b). Since a period of $162 \mathrm{~d}$ had elapsed for growth of $1.2 \mathrm{~cm}$ of this vibrissa, an average growth rate of $0.075 \mathrm{~mm} \mathrm{~d}^{-1}$ was obtained for the Poco vibrissa during the period from December to May. In addition, assuming that the $\delta^{15} \mathrm{~N}$ peak value of $61.3 \%$ at $1.0 \mathrm{~cm}$ had reached isotopic equilibrium, and the decline of $\delta^{15} \mathrm{~N}$ values along the length of this vibrissa, e.g. $52.6 \%$ at $0.8 \mathrm{~cm}, 17.6 \%$ at $0.6 \mathrm{~cm}, 16.4 \%$ at $0.2 \mathrm{~cm}$, and $15.3 \%$ at the base $(0.0 \mathrm{~cm})$, fit an exponential decay model, a half-life for glycine tracer turnover was estimated as $47.1 \mathrm{~d}$. This turnover rate was comparable to those estimated for red blood cells (Zhao 2002).

The second tracer experiment demonstrated that ${ }^{15} \mathrm{~N}$-enriched markers were evident in all vibrissae of the 3 seals, when vibrissae were collected on 5 Sep- 


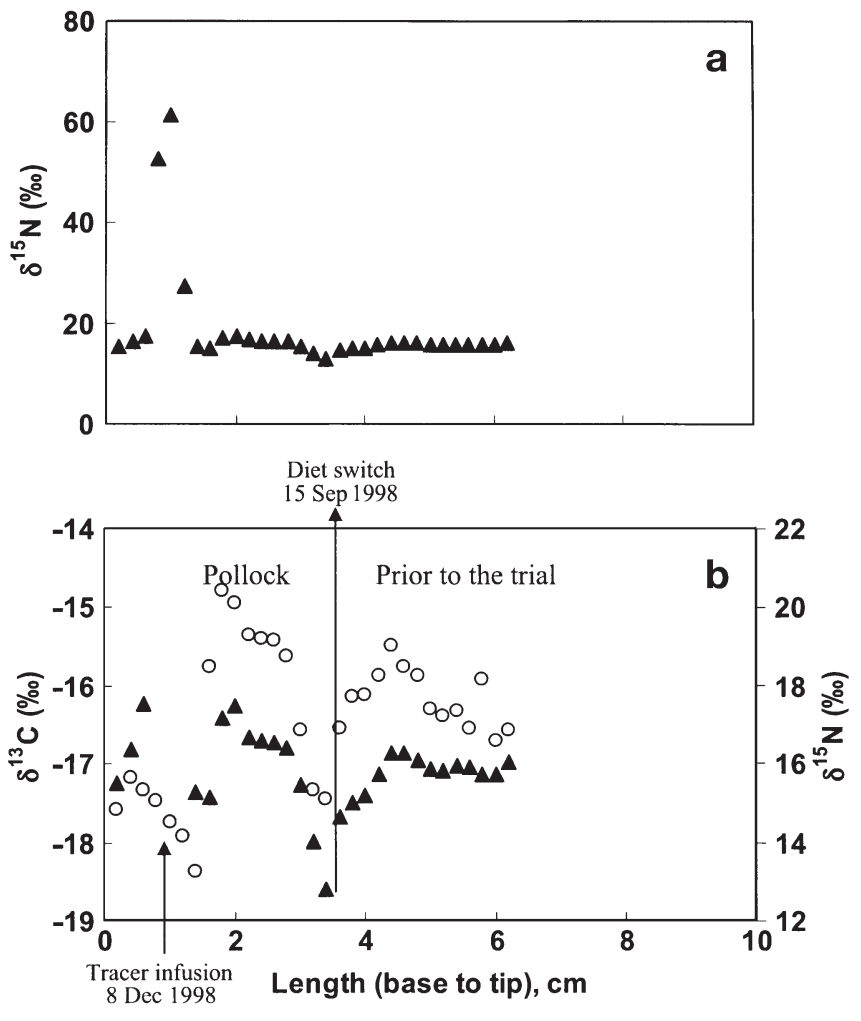

Fig. 2. Phoca vitulina. $\delta^{13} \mathrm{C}(\mathrm{O})$ and $\delta^{15} \mathrm{~N}(\mathbf{\Delta})$ in the vibrissa from Poco sampled on 18 May 1999, 162 d following the ${ }^{15} \mathrm{~N}$-glycine infusion. (a) $\delta^{15} \mathrm{~N}$-enriched marker and (b) covariations with $\delta^{13} \mathrm{C}$ values (highly enriched $\delta^{15} \mathrm{~N}$ value could not be seen due to smaller scale). Data at the base of vibrissae length $(0 \mathrm{~cm})$ represent the most recently grown vibrissae

tember 2000; a period of $77 \mathrm{~d}$ had elapsed following a second dosage of ${ }^{15} \mathrm{~N}$-labeled essential amino acid infusions on 21 June 2000 (Fig. 4). The estimated vibrissa growth rates were respectively $0.58 \mathrm{~mm} \mathrm{~d}^{-1}$ for Pender and $0.36 \mathrm{~mm} \mathrm{~d}^{-1}$ for Snapper. Compared to $\delta^{15} \mathrm{~N}$ patterns and values as high as $66.7 \%$ ond $54.9 \%$ in vibrissae from Pender and Snapper, $\delta^{15} \mathrm{~N}$ patterns in the vibrissa from Poco differed, with the highest $\delta^{15} \mathrm{~N}$ of $22.1 \%$ at the tip. We assume that this vibrissa might commence growth several days after the ${ }^{15} \mathrm{~N}$-valine infusion when the serum $\delta^{15} \mathrm{~N}$ pool was less enriched due to exponential decay of isotopic enrichment in serum (Zhao 2002). Hence, the ${ }^{15} \mathrm{~N}$ marker was still evident at the tip at much lower $\delta^{15} \mathrm{~N}$ values. The estimated growth rate of this vibrissa was up to $0.78 \mathrm{~mm} \mathrm{~d}^{-1}$.

\section{Natural abundance of $\delta^{13} \mathrm{C}$ and $\delta^{15} \mathrm{~N}$ in response to different diets}

As shown in Figs. 1 \& 3, no enriched ${ }^{15} \mathrm{~N}$ markers were observed in vibrissae from all 3 seals sampled on

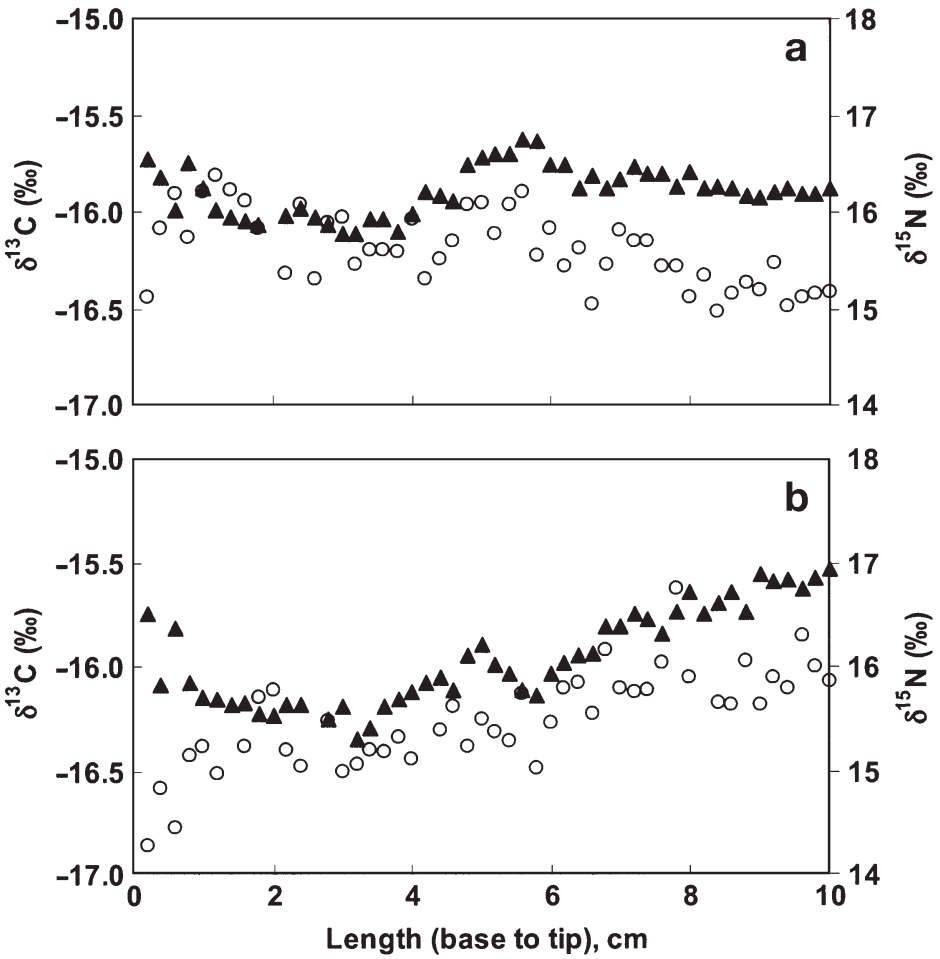

Fig. 3. Phoca vitulina. $\delta^{13} \mathrm{C}(\mathrm{O})$ and $\delta^{15} \mathrm{~N}(\boldsymbol{\Delta})$ in vibrissae sampled on 15 September 1999 from (a) Snapper and (b) Poco. Data at the base of vibrissae length $(0 \mathrm{~cm})$ represent the most recently grown vibrissae

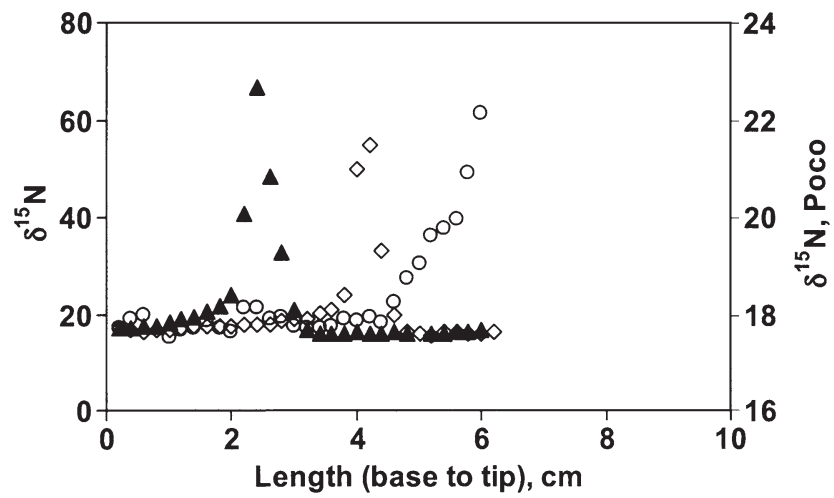

Fig. 4. Phoca vitulina. $\delta^{15} \mathrm{~N}$ values in vibrissae following the second dosage of ${ }^{15} \mathrm{~N}$-labeled essential amino acid infusions. Vibrissae were sampled on 5 September 2000 from Pender $(\diamond)$, Snapper $(\mathbf{\Delta})$ and Poco (o). Data at the base of vibrissae length $(0 \mathrm{~cm})$ represent the most recently grown vibrissae

15 September 1999. Any changes in $\delta^{13} \mathrm{C}$ and $\delta^{15} \mathrm{~N}$ values along the length of these vibrissae should reflect changes in the diet of the seals. Although several batches of herring and pollock had been used during the 2 yr period, $\delta^{13} \mathrm{C}$ values in pollock were generally more enriched, by $2 \%$, than those in herring, but no 
statistically significant differences in $\delta^{15} \mathrm{~N}$ values were found between the 2 fish diets (Zhao 2002). Hence, minor variations in $\delta^{13} \mathrm{C}$ along the length of each vibrissa indicate a constant diet during the period of the vibrissa growth. As Table 1 shows, except for Snapper who was fed on a constant diet of an equal mix of herring and pollock, both Pender and Poco switched their diet to alternative prey fish on 16 May 1999. Fairly uniform carbon isotopic compositions along the length of these 3 vibrissae imply that no diet switch occurred during the period of vibrissa growth, supporting, indirectly, the assumption that these vibrissae were newly grown and started in late May or June.

Fig. 3 also demonstrates that $\delta^{13} \mathrm{C}$ values co-varied with $\delta^{15} \mathrm{~N}$ values, except for pronounced opposite variations near the base of vibrissae, where $\delta^{13} \mathrm{C}$ values were more depleted and $\delta^{15} \mathrm{~N}$ values more enriched. In addition, little variations in $\delta^{13} \mathrm{C}$ values along the length of each vibrissa sampled on 5 September 2000 mirrored the constant diet of different seals (Fig. 5a) and, again, supported the above assumption. Consistent $\delta^{13} \mathrm{C}$ patterns were found in both vibrissae and serum (Fig. 5b). Moreover, the depleted $\delta^{13} \mathrm{C}$ values near the base of all these vibrissae exhibited similar patterns as those mentioned earlier.
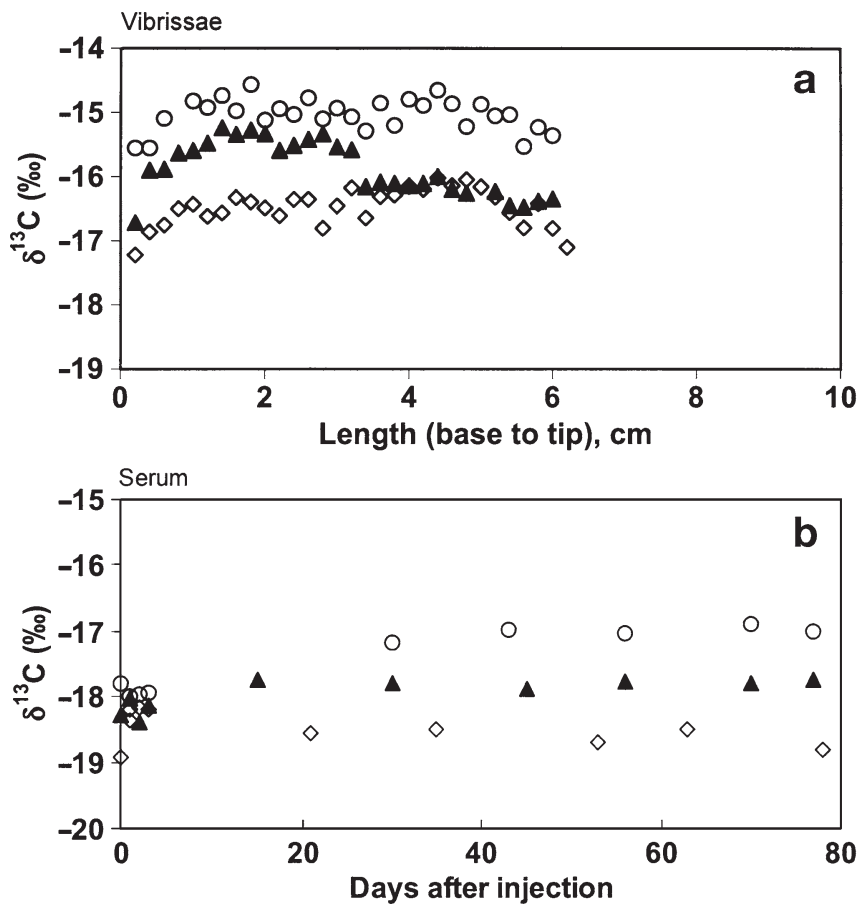

Fig. 5. Phoca vitulina. $\delta^{13} \mathrm{C}$ in (a) vibrissae sampled on 5 September 2000 and (b) serum collected during the same period of vibrissa growth from 16 May 2000 to 5 September 2000. Pender $(\diamond)$, Snapper $(\boldsymbol{\Delta})$ and Poco (०). Data at the base of vibrissa length $(0 \mathrm{~cm})$ represent the most recently grown vibrissae

\section{DISCUSSION}

The results of this study confirm early findings that harbor seals shed their vibrissae annually. Tracer experiments verify that vibrissae replacement may occur in May or June, depending on individual seals. For instance, Pender shed his vibrissae earlier than Poco, as elucidated by the following evidence: (1) The vibrissa from Poco sampled on 18 May 1999 still retained the previous December's ${ }^{15} \mathrm{~N}$-enriched marker, but no December marker was evident in the vibrissa from Pender sampled on 20 May 1999. (2) New vibrissae from Poco had not started growth until 21 June 2000, since only the tip of the vibrissa from Poco, sampled on 5 September 2000, was labeled with a much lower $\delta^{15} \mathrm{~N}$ value (see Fig. 4). This conclusion is in good agreement with the field observation that harbor seal pups in Prince William Sound usually shed vibrissae in May (T. Mau pers. comm.).

Our data also suggest that growth rates of vibrissae varied with seasons, ranging from $0.075 \mathrm{~mm} \mathrm{~d}^{-1}$ from December to May to up to $0.78 \mathrm{~mm} \mathrm{~d}^{-1}$ for newly grown vibrissae from May or June to September. New vibrissae grow much faster during the period of replacement and all vibrissae were longer than $6 \mathrm{~cm}$ by September, probably due to critical roles of vibrissae for seals to navigate and forage for food in murky and dark waters (Dehnhardt \& Kaminski 1995, Dehnhardt et al. 1998). The aforementioned authors found that well-developed vibrissae are movement-sensitive, having a rich supply of sensory nerves at the base of each vibrissa.

Hirons et al. (2001) suggested that harbor seals vibrissae grow irregularly and concluded that new vibrissae grow from fall to spring, but cease growing in June, with an average growth rate of $0.33 \mathrm{~mm} \mathrm{~d}^{-1}$. This mistaken conclusion arose from the tracer infusion time (4 June) of their experiments because seals could have shed their vibrissae either before or after this infusion date, based on evidence from this study. In fact, data obtained from their experiments supported our estimated time for vibrissa re-growth. For instance, Hirons et al. (2001) observed that there were no enriched glycine markers in harbor seal HS-P vibrissae clipped either on 5 November 1996 or 9 July 1998, in spite of high enrichments of carbon and nitrogen incorporation found in the blood'. This is because seals replace their vibrissae annually (for the vibrissa collected on 9 July 1998) and might lose enriched markers by shedding their vibrissae after 4 June 1996 (for the vibrissa collected on 5 November 1996). However, 'one identical enriched glycine marker was observed in harbor seal HS-N vibrissae sampled on 29 August 1996 and 5 November 1996, despite two dosages of enriched glycine that were infused on 9 January 1996 and 4 
June 1996, respectively'. The authors assumed that the single marker was the result of January's infusion based on blood isotope data, and commented that 'the second dose given on 4 June did not incorporate into vibrissae and vibrissae growth ceased altogether in June, due to the similar locations of the marker in vibrissae sampled in August and November'. However, the ${ }^{15} \mathrm{~N}$ marker should still have been evident at the base of the vibrissa, even though vibrissa growth had ceased. A possible explanation is that the harbor seal, named HS-N, shed most of its vibrissae before 4 June 1996. In that case, vibrissae sampled in August and November had both grown after 4 June, and the identical markers in these 2 vibrissae represented June's glycine infusion and an approximately $0.60 \mathrm{~mm} \mathrm{~d}^{-1}$ growth rate through August (see Fig. 1 in Hirons et al. 2001). This growth rate was comparable to the rapid growth rate of $0.58 \mathrm{~mm} \mathrm{~d}^{-1}$ found for Pender in this study. Moreover, an average growth rate of $0.08 \mathrm{~mm}$ $\mathrm{d}^{-1}$ from September to April, estimated from a recaptured wild seal (see Fig. 4 in Hirons et al. 2001), was in good agreement with a growth rate of $0.075 \mathrm{~mm} \mathrm{~d}^{-1}$ from December to May of our captive seals, suggesting that there were no major differences in vibrissa growth rates between captive and wild harbor seals.

Stable isotope ratios in harbor seal vibrissae provide an archive of temporal ecological records during the period of vibrissa growth. Co-variations in $\delta^{13} \mathrm{C}$ and $\delta^{15} \mathrm{~N}$ values along the length of vibrissae reflect similar effects of diets or habitat changes on metabolism of harbor seals. Particularly carbon and nitrogen isotopic composition in the vibrissa from Poco sampled on 18 May 1999 (see Fig. 2b) recorded all the events occurring during the period of its growth, i.e. the ${ }^{15} \mathrm{~N}$-glycine infusion event on 8 December 1998, diet switch from predominantly herring to exclusively pollock on 15 September 1998, and an opportunistic diet of wild fish species prior to captivity. It is worth noting that it is probably not uncommon that $\delta^{13} \mathrm{C}$ and $\delta^{15} \mathrm{~N}$ near the base of vibrissae varied in opposite directions. Similar patterns were also documented in captive harp seals (Hobson et al. 1996).

Since vibrissae can be sampled less invasively and archive ecological changes over a relatively long metabolic period, vibrissa segmental isotopic analysis provides a more flexible tool for studying foraging ecology of wild harbor seals, despite the varying seasonal growth rates and annual replacements. In addition, our data show that ${ }^{15} \mathrm{~N}$-labeled glycine and 3 essential amino acids can rapidly incorporate into protein synthesis of seal vibrissae following their intravenous infusions, and the half-life for ${ }^{15} \mathrm{~N}$-glycine turnover rate can be up to $47.1 \mathrm{~d}$. Thus, infusion of ${ }^{15} \mathrm{~N}$-labeled amino acids, particularly glycine, may serve as a longterm marker to track foraging ecology of wild seals and their vibrissa growth rates. The most important consideration with the use of vibrissa segmental isotopic analysis and ${ }^{15} \mathrm{~N}$-labeled tracer studies is the choice of sampling and infusion time. For example, vibrissae that represent a year's growth might be collected in May prior to annual replacements. In this case, variations in $\delta^{13} \mathrm{C}$ and $\delta^{15} \mathrm{~N}$ values along most of the length of vibrissae will represent last year's late spring and summer dietary and habitat information. Feeding information during winter and early spring are likely confined to a narrow band near the base.

In summary, this study confirms that harbor seals shed their vibrissae annually in May or June and regrew them rapidly, depending on environmental factors and individual physiological conditions. The process of replacements might complete within a very short period because new vibrissae grow very fast at up to $0.78 \mathrm{~mm} \mathrm{~d}^{-1}$, compared to a much slower growth rate during winter and early spring seasons. The $\delta^{13} \mathrm{C}$ and $\delta^{15} \mathrm{~N}$ values along vibrissa length co-varied and provided a temporal record of diets over a much longer period than other tissues, such as blood. Thus, vibrissa segmental isotopic analysis provides a more flexible tool for studying the foraging ecology of wild seals, particularly during the rapid growth period from late spring to summer or even fall.

Acknowledgements. We thank M. A. Castellini's research group and staff of the Alaska SeaLife Center (ASLC) for assistance with sample collection. Vibrissa samples were authorized through EVOS project no. 341 through M. A. Castellini and collected under MMPA permit no. 881-1443 with UAF and ASLC-IACUC approval. The research described in this paper (Restoration Project no. 371) was supported by the Exxon Valdez oil spill Trustee Council. However, the findings and conclusions presented by the authors are their own and do not necessarily reflect the views or position of the Trustee Council.

\section{LITERATURE CITED}

Alaska Sea Grant (1993) Is it food? Addressing marine mammal and seabird declines. Workshop Summary Alaska Sea Grant Report 93-01. Alaska Sea Grant College Program, University of Alaska Fairbanks, Fairbanks, AK

Anderson PJ, Piatt JF (1999) Community reorganization in the Gulf of Alaska following ocean climate regime shift. Mar Ecol Prog Ser 189:117-123

Beamish RJ (1993) Climate and exceptional fish production off the west coast of North America. Can J Fish Aquat Sci 50:2270-2291

Burton RK, Koch PL (1999) Isotopic tracking of foraging and long-distance migration in northeastern Pacific pinnipeds. Oecologia 119:578-585

Dehnhardt G, Kaminski A (1995) Sensitivity of the mystacial vibrissae of harbor seals (Phoca vitulina) for size differences of actively touched objects. J Exp Biol 198: $2317-2323$

Dehnhardt G, Mauck B, Bleckmann H (1998) Seal whiskers detect water movements. Nature 394:235

Frost KJ, Lowrey LF, Sinclair EH, VerHoef J, McAllister DC 
(1994) Impacts on distribution, abundance and productivity of harbor seals. In: Loughlin TR (ed) Marine mammals and Exxon Valdez. Academic Press, San Diego, p 97-118

Hirons A, Schell DM, St Aubin D (2001) Growth rates of vibrissae of harbor seals (Phoca vitulina) and Steller sea lions (Eumetopias jubatus). Can J Zool 79:1053-1061

Hobson KA, Clark RG (1992) Assessing avian diets using stable isotopes. I. Turnover of ${ }^{13} \mathrm{C}$ in tissues. Condor 94:181-188

Hobson KA, Schell DM, Renouf D, Noseworthy E (1996) Stable carbon and nitrogen isotopic fractionation between diet and tissues of captive seals: implications for dietary reconstructions involving marine mammals. Can J Fish Aquat Sci 53:528-533

Hobson KA, Sease JL, Merrick RL, Piatt JF (1997) Investigating trophic relationships of pinnipeds in Alaska using stable isotope ratios of nitrogen and carbon. Mar Mamm Sci 13:114-132

Kurle C (2002) Stable isotope ratios of blood components from captive northern fur seals (Callorhinus ursinus) and their diet: applications for studying the foraging ecology of wild otariids. Can J Zool 80:902-909

Editorial responsibility: Otto Kinne (Editor),

Oldendorf/Luhe, Germany
Kurle C, Worthy GAJ (2001) Stable isotope assessment of temporal and geographic differences in feeding ecology of northern fur seals (Callorhinus ursinus) and their prey. Oecologia 126:254-265

Lesage V, Hammill MO, Kovacs KM (2001) Marine mammals and the community structure of the Estuary and Gulf of St. Lawrence, Canada: evidence from stable isotope analysis. Mar Ecol Prog Ser 210:203-221

Pitcher K W (1990) Major decline in number of harbor seals, Phoca vitulina richardsi, on Tugidak Island, Gulf of Alaska. Mar Mamm Sci 6:121-134

Rosen DAS, Trites AW (2000) Pollock and the decline of Steller sea lions: testing the junk food hypothesis. Can J Zool 87: $1243-1250$

Tieszen LL, Boutton TW, Tesdahl KG, Slade NA (1983) Fractionation and turnover of stable carbon isotopes in animal tissues: implications for ${ }^{13} \mathrm{C}$ analysis of diet. Oecologia 57: $32-37$

Zhao L (2002) Tracing amino acid metabolism of harbor seals (Phoca vitulina) using stable isotope techniques. PhD thesis, University of Alaska Fairbanks, Fairbanks, AK

Submitted: March 9, 2004; Accepted: July 1, 2004

Proofs received from author(s): October 6, 2004 